\title{
PRESENTACIÓN. LOS JUEGOS TRADICIONALES: UNA APROXIMACIÓN DESDE LA HISTORIA DE LA EDUCACIÓN
}

\section{Presentation. Popular games: an approximation from the History of Education}

Antonio S. Almeida Aguiar

Universidad de Las Palmas de Gran Canaria

Juan Francisco Cerezo Manrique

Universidad de Salamanca

Correo-e: jfcm@usal.es

$\mathrm{E}$

L JUEGO ESTÁ VINCULAdO A LA EXISTENCIA HUMANA. Esta no se puede entender sin el componente lúdico. No es extraño, por tanto, que desde distintos ámbitos de conocimiento, especialmente desde la historia, la antropología y la sociología, se hayan interesado en las distintas manifestaciones físicas del ser humano, y especialmente en el juego. El ejercicio físico motórico del ser humano no es solo una manifestación biológica, sino que responde a una incuestionable dimensión cultural. De esta forma, hay abundantes teorías que relacionan el juego y la cultura. A finales del siglo XIX, varios antropólogos, entre los que podemos citar a Morgan y Taylor, establecieron en su momento la siguiente clasificación: juegos de habilidad física, en los que el éxito se determina por las actividades motrices de los jugadores; juegos de estrategia, en los que el éxito se determina por la opción racional entre varios tipos de acción posible; juegos de azar, en los que el éxito se determina por adivinanzas o por un artefacto incontrolado como una rueda o un dado ${ }^{\text {I }}$ Otros autores relevantes de esta dimensión cultural del juego, y que aparecen recogidos igualmente en algunas de las aportaciones de este monográfico, son Schiller, Cox, Caillois y especialmente Huizinga con su Homo ludens. Como punto de inicio, suele ser habitual para el análisis del concepto de juego la definición que Huizinga realizó en los años treinta del pasado siglo:

Acción o actividad libre, realizada dentro de ciertos límites fijados en el tiempo y en el espacio, según una regla libremente aceptada, pero completamente imperiosa;

I Blanchard, K. y Cheska, A.: Antropología del deporte, Barcelona, Bellaterra, 1986. 
acción que tiene fin en sí misma y que va acompañada de tensión y alegría y con la conciencia de ser de otra manera a la que se es en la vida corriente ${ }^{2}$.

Pero no solo se ha relacionado el juego como generador de cultura, sino que otros investigadores han establecido una cadena evolutiva de prácticas motrices que sugieren que el deporte es el producto final de la misma, e incluso llegan a definir una transición histórica perfectamente identificable de transformación del juego al deporte, como señala Bertrand During.

$\mathrm{Y}$ es que, desde las primeras civilizaciones, se han ido definiendo y construyendo toda una serie de juegos. Los antiguos griegos se referían al juego como pasatiempo, de forma improvisada, sin planificación previa, utilizando el concepto paidia. Posteriormente, Platón se esfuerza en delimitar el concepto de paidia y paideia, entre el pasatiempo y la cultura. $\mathrm{O}$ el uso de un tipo particular de prácticas lúdicas, los juegos agonales en el mundo griego, o los ludi en la civilización romana, como el munus, juegos ritualizados que establecen una relación entre lo lúdico y lo sagrado.

El gran momento de la literatura del juego coincidirá con el humanismo renacentista. No es de extrañar que el cambio de la visión del ser humano, con un renovado concepto antropocéntrico de la existencia, se traduzca en un interés razonado de todo aquello que rodea la vida humana, incluidos los juegos de la infancia. Una de las primeras fórmulas utilizadas para conocer el universo lúdico de la infancia fue el diálogo literario. A través de la conversación de los personajes protagonistas, sobre todo en libros escolares diseñados como material didáctico, se dan a conocer muchos de estos juegos para captar el interés de los educandos. El Renacimiento había creado el coloquio escolar con el objetivo principal de enseñar latín a los jóvenes, siguiendo un método activo a base de diálogos entre el profesor y el alumno. Es el caso de la obra Paedologia (I518), del humanista alemán Petrus Mosellanus, o el texto de Erasmo de Rotterdam, Familiarum colloquiorum formulae (I5I8). El éxito de esta última obra llevó a sucesivas ediciones en años posteriores, ampliando el sentido moralizante de su contenido a través de nuevos diálogos. Tanto es así, que en la publicación de I522 indica que la finalidad que guía al autor es «non solum ad linguam puerilem expoliendam, verum etiam ad vitam instituemdam»`. A través de los coloquios y sus diálogos, podemos constatar el interés no solo por los juegos infantiles, sino también cómo jugaban durante el recreo. La forma de diálogo también es la elegida por el humanista valenciano Luis Vives en Lingua latinae exercitatio (1538). Más conocida como Diálogos escolares o simplemente Diálogos, establece las seis «leyes del juego»: cuándo se ha de jugar, con quién se ha de jugar, a qué juego se ha de jugar, qué se ha de apostar, de qué modo se ha de jugar y cuánto tiempo se ha de jugar. El juego es analizado como elemento necesario para el equilibrio del ser humano, de la mente y el cuerpo. El juego recreativo como elemento

Huizinga, J.: Homo ludens, Madrid, Alianza, 1984, p. 26.

Del Rey, S.: Diálogo y traducción. Los Coloquios erasmianos en la Castilla del siglo XVI, Tübingen, Narr-Verlag, 20I5, p. 93. Traducción de la cita en latín: «No solo para perfeccionar la lengua de los muchachos, sino también para prepararlos para la vida». 
PRESENTACIÓN. LOS JUEGOS TRADICIONALES: UNA APROXIMACIÓN DESDE LA HISTORIA DE LA EDUCACIÓN

ANTONIO S. ALMEIDA AGUIAR Y JUAN FRANCISCO CEREZO MANRIQUE

de socialización con el grupo de iguales con un fin en sí mismo, sin otro objetivo que el disfrute de su práctica. Para su disfrute, las reglas deben ser las suficientes para la comprensión de los participantes. La complejidad de las mismas rompería el momento lúdico. También se contempla el juego dirigido por el maestro, con la motivación extrínseca a la práctica motórica, como es el premio. El mismo debe ser alegre, jovial, cortés, alejado del engaño ya que el juego es entendido como recreo y satisfacción. En definitiva, la práctica del juego es considerada un medio básico para la educación integral del ser humano ${ }^{4}$. Otra de las obras más interesantes que aborda los principios éticos y morales del juego, y que comentaremos posteriormente al ser objeto de un estudio en este monográfico, es el Tratado del juego (I559), de Francisco de Alcocer.

El jesuita toledano Pedro Pablo de Acevedo, quien en Colloquio (1587), representada en Sevilla para el cardenal Rodrigo de Castro, cuando lo hicieron protector de la Anunciata del Colegio de San Hermenegildo, utiliza como personaje protagonista a un adolescente conocedor de juegos y entretenimientos. Así, va enumerando entre las prácticas lúdicas el correr, luchar y ver quién derriba, la chueca, el tejo, el garrote, el esconder, el tumbo, el toro de las coces, etc.5. En una misma línea podríamos situar al también jesuita Antonii Van Torre con Dialogi familiares litterarum tironibus in pietatis, scholae, ludorum exercitationibus utiles $\mathcal{E}$ necessarii (I657). Con el mismo objetivo que los anteriores, fue utilizado como texto de cabecera en los colegios jesuitas. El interés de esta obra en relación a los juegos es precisamente el capítulo tercero «Ad lusus spectans», ya que está dedicado íntegramente a las prácticas lúdicas de la infancia. El diálogo en latín era la base para la comunicación en los juegos del recreo: «Latine semper loquitor, etiam inter lusum».

La obra de François Rabelais, si bien no se plantea como diálogo, es una extraordinaria recopilación de juegos infantiles del primer tercio del siglo xvi. Gargantua et Pantagruel (I534) es un conjunto de cinco novelas que narra la vida de estos personajes de forma satírica: la historia de dos gigantes, padre e hijo. El capítulo xxir lleva por título «De los juegos de Gargantúa», y algunos autores han contabilizado más de doscientos. No solo presenta una versión casi enciclopédica de los juegos, sino que además en otros capítulos, como el xxiII, «De cómo Gargantúa fue instruido por Ponócrates en tal disciplina que no perdía hora del día», termina por contextualizarlos:

Terminada la lectura o lección magistral, salían a la calle, siempre conversando sobre los temas de la misma, y una veces en la Braque, otras en un prado, se deportivaban jugando al balón, a la pelota-mano o a la trigona, ejercitando galanamente el cuerpo, como antes lo hicieron con el espíritu [...] jugaba al balón y lo hacía botar

Vives, L.: Diálogos, Madrid, Espasa-Calpe, I959.

Piñero, P. (ed.): De la Canción de Amor Medieval a las Soleares, Sevilla, Universidad de Sevilla, 2004, p. 268; Pelegrín, A.: Repertorio de antiguos juegos infantiles. Tradición y literatura bispánica, Madrid, Consejo Superior de Investigaciones Científicas, 1998.

VAn Torre, A.: Dialogi familiares litterarum tironibus in pietatis, scholae, ludorum exercitationibus utiles E necessarii, Amberes, Henrici, 1750, p. 3. Traducción de la cita en latín: «Habla siempre latín, también en los juegos». 
en el aire, tanto con el pie como de puño. Luchaba, corría, saltaba [...] Jugaba a las barras en competición con los más forzudos [... $]^{7}$.

Junto a estos textos, otros muchos van incorporando imágenes que acompañan a las descripciones de los coloquios. Es el caso de Les Jeux et plaisirs de l'enfance (1667) de Bouzonnet-Stella, el de Jacob Cats con Silenus Alcibiadis sive Proteus (I6I8) o quizá la más conocida Orbis sensualim pictus (I658) de Comenius. Este último es un libro de texto a modo de enciclopedia para niños, que abarca conocimientos de ciencias sociales y naturales. En la edición que hemos podido consultar, los grabados referidos a las prácticas lúdicas se centran entre los capítulos XXXI-XXXvi. Los juegos que aparecen descritos, tanto en el texto como a través de las imágenes, están organizados conforme a su significado. Así, en un primer capítulo encontramos actividades relacionadas con los volatineros, entre ellos los saltos, acrobacias, ejercicios de equilibrio, trapecios, etc. En un segundo momento, juegos en la escuela, en la que al patio de recreo se le denomina palestra. En el grabado se encuentran ejercicios de lucha, esgrima, boxeo, etc. El siguiente se dedica al tenis, mostrando las instalaciones y los complementos necesarios para la práctica del juego de la raqueta. A los juegos de mesa los denomina juegos de azar. Los últimos grabados reflejan otras prácticas de niños, algunas vinculadas al invierno como el esquí y otras a los juegos en la naturaleza, utilizando zancos, bolos, juegos de pelota, carreras, etc. ${ }^{8}$. En una misma línea editorial, se encuentra The complete gamestre (1674), de Charles Cotton.

Con el siglo xvinI, se produce una doble corriente en las obras literarias y su manera de representar al juego. Por un lado, nos encontramos una tradición enciclopédica, con un objetivo más popular que erudito en cuanto a su contenido, al menos en sus orígenes, y que se centra principalmente en juegos de mesa y de salón, más que en juegos motóricos, aunque, con el paso del tiempo, estos también se fueron incorporando. Entre ellas podemos citar la Académie universelle des jeux (1730), aunque la más conocida y en la que se ve una mayor cientificidad es la Encyclopaedia ou Dictionnaire raisonné des sciences, des arts et des métiers, publicada por Diderot y D'Alembert (I75I-I772). Entre los muchos ámbitos de conocimiento que abarca, uno de los volúmenes lo dedica específicamente a las Arts académiques, équitation, escrime, danse, et art de nager. Prácticas como la pesca, la caza, la pesca, el billar o el jeu de paume forman parte de sus contenidos.

En un contexto en el que se restringían los espacios públicos para la práctica de los juegos de los niños de clase alta, el espacio escolar, en la naturaleza, aparece como un escenario recuperado para los juegos tradicionales. En la Europa del siglo xviII, la educación infantil y los juegos de la infancia tenía poco protagonismo

Rabelais, F.: Gargantúa, Barcelona, Editorial Juventud, 1972, pp. I44-I49. El braque es un frontón donde se jugaba a la pelota mano o pelota vasca. La trigona es un juego de pelota en que los jugadores se colocaban en trigon, triángulo.

8 Para los comentarios realizados a la obra de Comenius en el presente estudio, hemos consultado la edición de I705, que se encuentra localizada en la Boston Public Libray y disponible en https: //archive.org/details/johamoscommeniiooocome. 
ANTONIO S. ALMEIDA AGUIAR Y JUAN FRANCISCO CEREZO MANRIQUE

e interés en la vida diaria. Ya algunos autores como Rousseau plantean la infancia y su desarrollo educativo como elementos claves para el cambio social. El juego es entendido como parte de la propia naturaleza del niño que le valdrá como preparación a las responsabilidades que asumirá en la edad adulta. Sus reflexiones sobre la actividad lúdica de la infancia le llevan a definir una serie de factores en torno al juego: debe resultar placentero y útil en su instrucción; uso de materiales que formen parte del medio ambiente del niño; motivación extrínseca, a modo de la propuesta de Vives; explicaciones del juego de forma sencilla, ajustarse a las necesidades y habilidades del niño, etc. Además, tendría en cuenta la edad de los participantes, el sexo, el momento del día en que se realizaban, la finalidad de los mismos, así como el placer que la actividad lúdica genera en los participantes. Sin duda, El Emilio o de la Educación (1762) será la base para una larga tradición pedagógica en la que los juegos tradicionales se incorporarán como una pieza clave en las prácticas educativas de la infancia. Las prácticas corporales propuestas por Rousseau ponen al alumno en la escuela de la naturaleza: posturas, actitudes que se trabajan con caminatas, saltos, escaladas y ejercicios de equilibrios. Los juegos, las actividades cotidianas, las orientaciones del preceptor aseguran la educación física así concebida.

Los principios teóricos del pedagogo ginebrino adquieren una concepción más clara y más precisa, orientándose en una dimensión educativa real y práctica con una orientación moderna en la obra de Pestalozzi. Es la suya una pedagogía entresacada de la observación diaria, de la lucha de cada día. En Cómo Gertrudis enseña a sus hijos (I80I), expresa a su amigo Gessner, a través de catorce cartas, su intención de encontrar un método por el que se llegue fácilmente al pueblo para redimirlo de la miseria y la desigualdad. Distingue entre la intuición y el arte de la intuición, y termina opinando sobre la educación de los sentimientos morales y religiosos. Por otra parte, en Gertrudis, se interesa por una práctica en la que reflexionará en otros escritos y que lo han llevado a ser considerado como uno de los autores clásicos de la educación física. De hecho, uno de sus principios educativos se centra en la educación integral del ser humano, buscando la armonía entre el espíritu y la razón, entre la cabeza y el corazón. Así, en la carta XII dirigida a Gessner escribe sobre la necesidad de la destreza física a través del trabajo corporal como base para la capacitación de las habilidades en cualquier ámbito profesional. Años después, retomaría la educación corporal en Sobre la educación física como introducción a una propuesta de gimnasia elemental, en una serie de ejercicios corporales (1807). Sus reflexiones previas y el conocimiento profundo de las obras de Rousseau orientan las principales ideas en torno a la educación física. No es de extrañar, por este motivo, que parta de las disposiciones naturales del ser humano y de la educación de los sentidos como base para su propuesta educativa. La educación integral el sujeto (cuerpo y mente), como fin último de la pedagogía, tiene su primera fase de desarrollo en el entorno familiar. Al terminar esta fase, el niño habrá adquirido cierta autonomía, y esta autonomía se manifiesta de una manera natural en tres formas: una forma moral, con la independencia del corazón; una forma espiritual, con relación al pensamiento, y una forma 
PRESENTACIÓN. LOS JUEGOS TRADICIONALES: UNA APROXIMACIÓN DESDE LA HISTORIA DE LA EDUCACIÓN

ANTONIO S. ALMEIDA AGUIAR Y JUAN FRANCISCO CEREZO MANRIQUE

física, con la independencia corporal, centrada en la necesidad de desarrollar las capacidades motrices. Así, los juegos formarían parte de la denominada gimnasia natural o espontánea, es decir, ejercicios intrínsecos a la propia naturaleza humana: saltar, correr, lanzar, trepar, etc. ${ }^{9}$.

La otra gran corriente en estos momentos se inicia con la tradición filantropinista alemana. Es precisamente Gymnastik für die Jugend (1793), de Guths-Muths, en la que el juego tiene un nuevo tratamiento educativo. Esta obra se caracteriza por la recuperación de la tradición helénica, hasta el punto de que la palabra utilizada para denominar a la gimnasia en el alemán original utiliza la terminología griega gymnos, aunque los ejercicios que describe difieren de esta tradición y constituyen una formulación completamente distinta y entroncada con los nuevos conceptos físico-educativos. La orientación del tratado es fundamentalmente pedagógica, y en él se describen los ejercicios gimnásticos, algunos trabajos manuales y los juegos en función de su valor educativo, moral y médico. Esta obra tendrá una influencia en tratados posteriores, especialmente en el siglo XIx. Entre ellos, La gimnástica o escuela de la juventud (1807), de Durivier; Descripción de los juegos de la infancia (1818), de Naharro, o la Gimnástica del Bello sexo. Ensayos sobre la educación física de las jóvenes (I822 ${ }^{\mathrm{r}}$. Una característica común a todas ellas es la identificación de los juegos tradicionales con fines educativos. Otra es la utilización de grabados, iniciada ya desde el siglo xviII, para ilustrar las explicaciones de los juegos. Una cuestión relevante es la sugerencia que hace alguno sobre los juegos más adecuados para las señoritas. Y, por último, la prolija relación de juegos que recogen entre sus páginas, muchos de ellos coincidentes, como no podía ser de otra manera. Así, entre ellos podemos mencionar las cuatro esquinas, la pelota, las bochas, los bolos, la peonza, el peón, la cucaña, la rayuela, los saltos, el tejo, salto a la cuerda, el columpio, los aros, saltos, carretones, etc.

Algunos de los autores y juegos tradicionales mencionados en esta presentación centrarán la atención de los estudios que en el presente número podemos estudiar. Andrés Payà Rico centra su reflexión en «El juego popular y tradicional en la historia de la educación española contemporánea». Toma como referencia para su análisis uno de los autores clásicos para acercar el concepto de juego al de cultura: Huizinga y su obra Homo ludens. Esta aproximación conceptual deja paso a un estudio de obras clásicas que abordan los juegos populares y tradicionales en España desde finales del xix. Algunos de los autores más relevantes que aparecen en su trabajo son Ricardo Rubio, Pedro Alcántara García, Manuel Bartolomé Cossío, Domingo Barnés, etc. Todos ellos deudores de una tradición lúdica europea, especialmente de Inglaterra, Alemania, Francia, Bélgica y Suiza, que progresivamente fue incorporándose a las reflexiones y prácticas educativas de los intelectuales españoles, principalmente desde el ámbito pedagógico.

9 Almeida, A.: «Johann Heinrich Pestalozzi (1746-I827): biografía literaria y epistolar», El Guiniguada. Revista de Investigaciones y Experiencias en Ciencias de la Educación, 26 (2017), pp. I8-25. Disponible en http: //ojsspdc.ulpgc.es/ojs/index.php/ElGuiniguada/article/view/719.

ro Pelegrín, A.: «Juegos de aldea y de la niñez en textos hispánicos», en Irureta, P. (coord.): El juego en el libro antigno, Madrid, Universidad Politécnica de Madrid, 2000, pp. 23-52. 
Junto a estos profesionales, Payà Rico referencia a otros menos conocidos, pero relevantes por sus aportaciones, maestros de profesión, que igualmente utilizan la prensa pedagógica para la defensa de los juegos populares, como es el caso de los valencianos Natalia Castro de la Jara y Félix Martí Alpera; la institucionista Matilde García del Real, o, para el caso de Cataluña, destacados pedagogos como Eladi Homs, Antoni Sabater Mur o María Bardó. En este contexto, el territorio catalán es analizado como uno de los espacios privilegiados en la recuperación de la tradición lúdica en los primeros años del siglo xx.

Tras una primera etapa de concienciación e implantación del valor educativo de los juegos tradicionales, los cambios políticos en el territorio español tras el golpe de Estado franquista y la utilización de símbolos como la patria e identidad nacional sirven de campo de experimentación con una finalidad educativo-adoctrinadora. Los juegos populares pasarán a formar parte del discurso de lo nacional, de elemento de identificación patria con respecto a otros Estados europeos; se convierten en un símbolo más de la identidad nacional. Los cambios que se producen en la España aperturista a partir de la década de los setenta y la aprobación de la Constitución española de 1978 recogen en la nueva organización de las autonomías la revalorización lúdica de lo local. Al juego popular se une igualmente el interés de los juguetes tradicionales, permitiendo el desarrollo de la creatividad de la infancia, ya no solo a través del juego motor, sino con el uso de elementos complementarios con sentido lúdico. Las últimas décadas han ampliado el uso de los juegos tradicionales, destacando su papel de transmisor de cultura, ocupando espacios en la escuela y fuera de ella con fines educativos, teniendo como eje de actuación el disfrute, y aportando valores como la democracia, la libertad, el desarrollo humanos, etc.

Jorge Cáceres-Muñoz es el autor de «Presencia y relevancia del juego popular en el Boletín de la Institución Libre de Enseñanza». Un trabajo que, mediante el análisis histórico-pedagógico, detecta la permanencia en la referida publicación de un conjunto de artículos, nacionales y extranjeros, que se interesan por el juego popular, inscribiendo el estudio de estas prácticas en los debates epistemológicos que se suceden durante el siglo XIX para consolidar nuevas ciencias y disciplinas como es el caso del folklore. Por otra parte, en el BILE tienen cabida también los trabajos que tratan de armonizar la cultura nacional y la extranjera, conciliar lo tradicional con lo nuevo, apareciendo el juego como aglutinador de corrientes antropológicas, fisiológicas y pedagógicas. Del conjunto de aportaciones de los artículos analizados se va configurando una teoría que entiende el juego como una acción inherente al ser humano y que siempre se ha practicado, bien como medio de aprendizaje, para relacionarse con el mundo o como canal de comunicación con los demás.

En consecuencia, se considera que el juego reporta beneficios sociales, higiénicos y educativos. En su práctica confluyen lo moral, lo físico y lo intelectual. Por ello, se demanda su presencia en la escuela y fuera de ella, y se recomienda tanto para niños como para adultos, por lo que en otros artículos se reclaman instalaciones para la práctica de los juegos. Aparece también la preocupación por 
recuperar los juegos tradicionales en busca de sus raíces culturales y folklóricas. En orden a clarificar la gran variedad y diversidad de estas manifestaciones lúdicas, se ofrecen distintas clasificaciones teniendo en cuenta indicadores como la edad, el sexo, la tipología, el lugar donde se practican, etc. De la misma forma, se aportan comparaciones con otros juegos foráneos, aludiendo a las variedades lingüísticas que presentan. No se omiten, tampoco, las referencias a su significación histórica y mitológica.

Como conclusión, se constata que una buena parte de los trabajos aparecidos en el BILE resaltan la importancia del juego en la educación del niño, destacando la contribución al desarrollo armónico de su personalidad. Consiguientemente, se va a entender el juego como un elemento pedagógico, que, por ello, ha de ser practicado y utilizado en la escuela y que, como consecuencia, dará origen a una nueva pedagogía sobre el juego, que, a su vez, se constituirá en una de las aportaciones metodológicas más relevantes del krausoinstitucionismo.

Las aportaciones de Antonio S. Almeida Aguiar y Ulises Castro Núñez se concretan en el estudio de «Los juegos tradicionales y la educación en Canarias: de las propuestas del siglo xix a las regulaciones autonómicas». Coincidiendo con otras investigaciones, el interés de estos autores se centra en un primer momento en analizar y delimitar el campo conceptual del juego tradicional, a través de las aportaciones de diversos autores. Siguiendo un esquema cronológico, tratan de mostrar con distintas evidencias cómo se van incorporando los juegos tradicionales en la pedagogía del Archipiélago Canario. Ya los primeros escritos aparecidos en la prensa local del siglo xIX dejan de manifiesto el interés que los maestros más progresistas mostraban, más allá de las fronteras nacionales, por la utilización del juego. Pedagogos relevantes como José Cabrera Díaz o Baltasar Champsaur Sicilia no dudaron en centrar muchas de sus reflexiones en la importancia educativa del juego. La idea de libertad es uno de los pilares en los que se defiende la práctica del juego en el desarrollo educativo de la infancia. El juego aparece en este contexto como la base primaria de la educación física, con un fin pragmático, basado en teorías y principios prácticos que beneficiarían a la educación de la infancia. En otros casos, los autores estudiados justifican el juego relacionado más con su función catártica y de gastos de excedente de energía que con su vinculación a la gimnasia. Y, entre las diferentes actuaciones para su implantación, las colonias escolares se convirtieron en un espacio idóneo para verificar los beneficios del juego tradicional en la formación de los más jóvenes.

Siguiendo los mismos esquemas que en el resto del Estado español, con la llegada del franquismo, se produce una revalorización de los juegos tradicionales como símbolo de identidad. La búsqueda y la revalorización de «lo nacional», en relación a los juegos tradicionales, se resalta en la publicación en la prensa de Canarias de una circular del jefe del Servicio Nacional de Primera Enseñanza, Romualdo de Toledo y Robles (1938), en la que se dan instrucciones sobre las orientaciones que deben tener las distintas materias del currículo para este nivel educativo, instándose a la recuperación y ennoblecimiento de los juegos infantiles locales. Los juegos y deportes tradicionales de Canarias se han visto favorecidos 
PRESENTACIÓN. LOS JUEGOS TRADICIONALES: UNA APROXIMACIÓN DESDE LA HISTORIA DE LA EDUCACIÓN

ANTONIO S. ALMEIDA AGUIAR Y JUAN FRANCISCO CEREZO MANRIQUE

con la creación de la Comunidad Autónoma Canaria y la transferencia de Educación al Gobierno canario; de esta forma han sido incluidos de manera relevante entre los contenidos a impartir en los distintos niveles educativos. El ejemplo más significativo de este planteamiento en el archipiélago es la lucha canaria. En el imaginario idealizado de la población insular, reúne una serie de características que la relacionan con la población indígena canaria preeuropea: valor, nobleza y estética motriz. Una aportación a este estudio son las imágenes que lo acompañan, todas ellas contemporáneas a los documentos que se van trabajando desde principios del siglo $\mathrm{xx}$.

De interés resulta la propuesta de Jordi Brasó Rius y Xavier Torrebadella Flix titulada «El juego popular de las cuatro esquinas: 30 variantes para recuperar su uso en la educación del siglo XXI». Dentro de la importante tradición de recuperación del patrimonio lúdico, una de las formas más eficaces es la adaptación de los mismos al contexto actual, pero desde una respuesta crítica, no hegemónica. Para ejemplificar esta idea, los autores han centrado su análisis en el juego de las cuatro esquinas. Parten inicialmente de un estudio bibliográfico de cómo aparece este juego en el siglo xIx y principios del xx, utilizando para ello diferentes bases de datos, lo que les aporta un material lo suficientemente significativo para estructurar el desarrollo y la propuesta final. De gran tradición desde el siglo XviII, este juego ha sido destacado por numerosos tratadistas. Entre otros autores, Brasó y Torrebadella han destacado a Amar y Jayffret; el propio Vicente Naharro, autor ya mencionado en la primera parte de esta presentación, o las obras de Rementería, López o Villabrille. En todos estos tratadistas, aparecen características, con variaciones, del juego que es objeto de estudio. Al mismo tiempo, se sugieren recomendaciones, según el sexo que lo practique, así como las adaptaciones a las reglas. Estos elementos cambiantes, propios de los juegos, sin duda son el argumento ideal para las propuestas que los autores del artículo presentan para la práctica del mismo en el siglo xxI.

Y esta propuesta se sustenta ya no solo en el componente que hemos señalado con anterioridad, sino también en el marco teórico que desde hace años ha establecido Parlebás y la praxiología motriz. Esta disciplina analiza la lógica interna de los juegos, y amplía de esta manera la posibilidad de su transformación con la combinación de variables. Desde esta perspectiva, se plantean 30 variantes a partir de las variables de ser actividad realizada con compañeros, adversarios y un medio estable. Las modificaciones que realzan se centran en el espacio; el móvil; en los participantes, tanto compañeros como adversarios; la variación la motricidad-desplazamiento; la obligatoriedad de desplazamiento de los participantes, y variables para el trabajo de contenidos históricos, matemáticos, geográficos, etc.

El artículo de Enrique Jiménez Vaquerizo, «Retrospectiva histórica del juego y deporte tradicional a través de la cultura segoviana», tiene como primer objetivo rastrear el origen y la evolución seguida por dichas prácticas en un territorio determinado, como es el de la provincia de Segovia, con una serie de condiciones favorables para su inicio y desarrollo posterior. La confluencia de una amplia red de cañadas reales, los diversos factores generados por la economía de la Mesta 
(trashumancia, comercialización del paño, etc.), así como los continuos procesos de repoblación y asentamientos subsiguientes, explicarían el surgimiento, auge y permanencia de los juegos y deportes populares durante un largo periodo de tiempo, que, no obstante, encontraría síntomas de decadencia en la primera mitad del siglo xx. Aunque no se recobrará, íntegramente, la presencia y el papel que habían venido desempeñando, lo cierto es que, con los procesos migratorios que se producen en las décadas de los sesenta y setenta del pasado siglo, la nueva organización territorial de nuestro país y la inestimable ayuda de las instituciones escolares, los juegos y deportes populares vuelven a resurgir, si bien tendrán que compartir su protagonismo de antaño con nuevas manifestaciones deportivas.

Otra de las aportaciones que realiza este estudio es la descripción y ordenación de estos juegos y deportes utilizando, entre otros, criterios e indicadores como el estado evolutivo de niños y niñas, la edad, el sexo o la estación del año. Esta aproximación clasificatoria, no muy rígida, nos apercibe de la riqueza de estas prácticas por cuanto acompañan los acontecimientos más significativos de la vida de los niños y de su educación. También se dedica atención al permanente dilema de si ha de hablarse de juegos o deportes tradicionales. A través de esta reflexión, fundamentalmente conceptual, se establecen claras diferencias entre ambas realidades y se traza la progresiva evolución que se va experimentado a través del tiempo del juego hacia el deporte, considerado este último como más institucionalizado y no tan inherente a la propia condición del ser humano.

Finalmente, se aborda el papel que en la actualidad tiene la escuela para mantener y recuperar el patrimonio cultural en sus vertientes lúdicas y deportivas. En este sentido, la participación de las instituciones educativas es fundamental para reconducir el juego y el deporte tradicional según sus raíces históricas y culturales, realizando las propuestas didácticas precisas. Todo ello teniendo en cuenta que niños y niñas han de disfrutar plenamente de los juegos y recreaciones, que habrán de estar orientados hacia los fines de la educación. A este respecto se analizan también las condiciones y requisitos bajo los cuales los juegos y deportes resultan educativos.

Por último, el artículo de Ignacio López de Prado Ortiz-Arce, titulado «Instruyendo sobre la recreación: Alcocer y la moderación en el siglo xvi, clave en la educación para el juego», presenta y analiza las reflexiones y propuestas del franciscano F. de Alcocer recogidas en su Tratado del juego. En este libro, que puede ser considerado como un manual de referencia para la época, trata de poner orden y de instruir sobre las prácticas lúdicas, muy extendidas durante el siglo XIX y con efectos, frecuentemente, poco saludables cuando se trataba de los juegos de azar. Como consecuencia, se generará una legislación específica, que, al no ser interpretada siempre de la misma forma, introducirá cierta confusión en la regulación de las prácticas de juego.

Alcocer, alumno de la Universidad de Salamanca y discípulo de Francisco de Vitoria, fue respetado y considerado como un hombre de gran sabiduría. Poseía, también, un buen conocimiento de los juegos, en general, y practicaba algunos de ellos. Como humanista que era, con influencias de Vives y Nebrija, defiende que 
el juego es inherente al ser humano y muy conveniente para el crecimiento integral de las personas. Si ello es así, el juego, por su propia naturaleza, no es pecado, no ha de ser condenable. Dependerá del uso que se haga de él y de las consecuencias, sobre todo laborales y religiosas, que acarree. Pero al ser su práctica tan frecuente, los riegos de excesos aumentaban considerablemente. Ante esta situación, el propio Alcocer, las autoridades civiles y las religiosas proponen la moderación como clave en la educación del juego, y la mesura para impedir los perjuicios que ocasionaban su descontrolada práctica y la dependencia que producían algunos de ellos como las apuestas y los juegos de azar.

Estas circunstancias van a evidenciar la necesidad de regular el juego a través de normas civiles y canónicas, que no surtirían siempre el efecto deseado, por su arraigo consuetudinario, porque su aplicación era bastante laxa, porque el juego era muy accesible y porque había muchos intereses creados en torno al desarrollo del mismo. Se aporta, también, la descripción de algunos de los juegos más populares y de mayor relieve como el voltear, el juego de passa, passa y los matachines. 
